\title{
La CONAMURI: resistencia de mujeres rurales e indígenas en Paraguay
}

Marco Enrique González Ramos ${ }^{1}$

\section{RESUMEN:}

La Coordinadora Nacional de Organización de Mujeres Trabajadoras, Rurales e Indígenas (CONAMURI) es una organización autónoma de mujeres que actúa de forma independiente al movimiento campesino e indígena de Paraguay. Entender por qué ellas decidieron construir un espacio propio para luchar por sus reivindicaciones así como la constitución de género, clase y etnia como base de su organización son claves que permiten conocer el impacto de los ejes de desigualdad de nuestra sociedad que se entrecruzan en ellas. La teoría feminista y la poscolonial, con aportes desde la perspectiva interseccional, son las herramientas de análisis utilizadas a fin de lograr una visión multicultural necesaria para comprender el contexto de la lucha de estas mujeres indígenas y campesinas.

Palabras-clave: Mujeres Campesinas e Indígenas - Teoría Feminista Teoría Poscolonial - Interseccionalidad - Paraguay.

\section{RESUMO}

A Coordinadora Nacional de Organización de Mujeres Trabajadoras, Rurales e Indígenas (CONAMURI) é uma organização autônoma de mulheres que agem de forma independente do movimento camponês e indígena do Paraguai. Entender porque elas decidiram construir seu próprio espaço para lutar por suas reivindicações e também a constituição de gênero, classe e etnia como base da sua organização são chaves que permitem conhecer o impacto dos eixos de desigualdade da nossa sociedade que cruzam em elas. A teoria feminista e a pós-colonial, com aportes a

\footnotetext{
$1 \quad$ Mestrando do Programa de Pós-graduação em Sociologia da Universidade Federal do Paraná e Bolsista da CAPES/OEA. E-mail: $\underline{\text { m.gonzalezramos@hotmail.com }}$
} 
partir da perspectiva interseccional, são as ferramentas de análise utilizadas para conseguir uma visão multicultural necessária para compreender o contexto da luta destas mulheres indígenas e camponesas.

Palavras-chave: Mulheres Camponesas e Indígenas - Teoria Feminista Teoria Pós-colonial - Interseccionalidade - Paraguai.

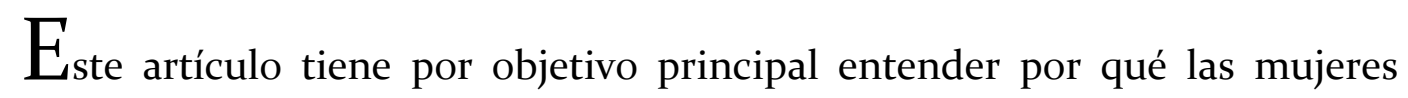
rurales e indígenas deciden organizarse de manera independiente con relación al espacio de resistencia encabezado por el movimiento campesino e indígena en Paraguay.

La Coordinadora Nacional de Organizaciones de Mujeres Trabajadoras, Rurales e Indígenas (CONAMURI) es un caso ejemplar que puede ser analizado desde dos aristas: la primera recae en la invisibilidad de la mujer dentro de los nuevos movimientos sociales. Esta característica que históricamente ha marcado a gran parte de estos movimientos alrededor del mundo es un reflejo de la sociedad patriarcal moderna inserta en estas nuevas formas de organización.

La segunda arista se refiere a la necesidad de las mujeres rurales e indígenas de encontrar un espacio para hablar desde su experiencia, en su propia voz. Esto se entiende a partir de lo que implica hacer resistencia no solo como mujer, sino como "del tercer mundo", y más aún, rural o indígena. Es decir, en el caso de la CONAMURI, la conjunción de elementos como género, clase y etnia que interactúan en varios niveles permite conocer el impacto de la desigualdad social en múltiples dimensiones.

La teoría feminista y la poscolonial, ambas a partir de la perspectiva de la interseccionalidad, son los instrumentos a través de los cuales se podrá explicar no solo la razón de esta autonomía sino también reconocer que 
estas mujeres son el punto en el que se entrecruzan los ejes de desigualdad de nuestra sociedad.

El análisis del movimiento de mujeres de la CONAMURI desde estas teorías busca destacar por un lado la visión multicultural que se puede alcanzar tras intercambio intelectual entre la teoría feminista y la poscolonial. Por otro, este análisis remarcará las consecuencias que el arraigado patriarcado ha ocasionado a las mujeres, profundizando aún más las condiciones de desigualdad a la que han estado sometidas históricamente.

Este artículo se divide en tres partes: la primera, presenta a la CONAMURI como organización de mujeres en rebeldía y resistencia; la segunda, expone el hecho de la invisibilidad de la mujer en los nuevos movimientos sociales. La última sección presenta un análisis desde la resistencia de ser mujer, del "tercer mundo", rural o indígena.

\section{La CONAMURI: mujeres en rebeldía y resistencia.}

"I tiempo ma kuña o mañavo ybate, anike pende py'amirĩ" (Ya es tiempo de que la mujer aspire más alto, no sean cobardes) Frase de aliento de uno de los dirigentes campesinos a sus compañeras en resistencia.

La Coordinadora Nacional de Organizaciones de Mujeres Trabajadoras, Rurales e Indígenas es una organización en Paraguay que nació “como respuesta a la necesidad de un espacio propio de las mujeres campesinas e indígenas para la defensa de sus derechos, y para la búsqueda de alternativas frente a la angustiante situación de pobreza, discriminación y exclusión por razones de clase, etnia y género” (CONAMURI, 2018). 
Esta organización tuvo su origen en el año 1999, durante el Día Mundial de la Mujer Rural (15 de octubre), momento en que se reunieron en Asunción más de 300 mujeres campesinas e indígenas y en donde se decidió articular esfuerzos para trabajar sus respectivas propuestas y reivindicaciones. En palabras de la CONAMURI (2009, p. 7) "por primera vez se unen las mujeres indígenas y campesinas, de dos mundos separados, aunque unidos por una historia común de exclusión en el Paraguay”.

Este punto es clave para el análisis realizado en este trabajo ya que la coyuntura política y social en la que se enmarca el nacimiento de la CONAMURI tiene por característica principal la desigualdad ocasionada por el modelo de acumulación de $\operatorname{capital}^{23}$ y la dictadura patriarcal, hecho que afectó aún más a las mujeres indígenas y campesinas, "quienes históricamente han sido invisibilizadas en su participación, aporte, intereses y realidades" (CONAMURI, 2009, p. 8).

A lo largo de la historia del Paraguay puede notarse la escasa o nula participación de la mujer en los distintos procesos que configuraron a la nación. En la época de la dictadura de Alfredo Stroessner (1954-1989), los movimientos campesinos fueron foco de persecución durante todo el régimen, lo que de alguna forma empeoró la situación de invisibilidad de las mismas:

La postergación histórica de las mujeres en el país es anterior a este oscuro período de nuestra historia, pero la Dictadura hizo de la exclusión social y la discriminación hacia las mujeres una

En Paraguay, este modelo es sustentado por el agronegocio, "un paquete tecnológico que contempla la venta de semillas transgénicas, agrotóxicos, fertilizantes y sofisticadas maquinarias para la depredación de bosques, preparación de suelo, fumigaciones extensivas incluida la aérea en manos de empresas transnacionales como Monsanto, Cargill, y otros". (CONAMURI, 2009, p. 8).

3 Paraguay es el cuarto exportador mundial de soja (USDA Feb/2018 - Zafra 2017/18, en CAPECO, 2018). 
política criminal, extremando la violencia en contra de las mujeres en las represiones, al mismo tiempo que las mantenía invisibles para la historia. Buscó desalentar la participación de las mujeres con la tortura sexual, con ocupaciones militares o un constante acoso hacia las comunidades (CONAMURI, 2009, p. 11).

En este contexto de represión y reorganización de movimientos de resistencia al régimen, las mujeres campesinas e indígenas fueron tomando más contacto con lo político, lo que les otorgó mayor conciencia de lo que estaba ocurriendo. Sin embargo, dentro de las propias organizaciones de resistencia, "el rol de las mujeres era invisible, no era reconocida ni valorada, y solo participaban en las organizaciones como cocineras" (CONAMURI, 2009, p. 12). Esto generó reclamos por parte de las mujeres, quienes también querían participar de los debates y toma de decisiones, pero ante los ojos de sus compañeros fue considerado como un acto de rebeldía y hasta de intento de división política de la causa.

Desde los años 8o, y tras el contacto internacional con organizaciones y encuentros mundiales de mujeres, las campesinas e indígenas comenzaron a relacionarse con otros grupos que atravesaban situaciones similares a las suyas. Este hecho en particular, así como el haber identificado la necesidad de encontrar un espacio propio para realizar la lucha por sus derechos a fin de acabar con la desigualdad fue lo que terminó de abrir sus ojos:

este proceso fue importante para identificar la necesidad de un espacio propio a nivel nacional para las mujeres rurales e indígenas, para quienes veníamos participando en organizaciones mixtas [...] Las mujeres que participaron en estos espacios de encuentro y discusión tomaron conciencia de que las mujeres eran doblemente oprimidas y explotadas, y desde entonces se fue profundizando la idea de que sin un espacio propio, las mujeres difícilmente pueden desarrollar sus capacidades y su participación a plenitud (CONAMURI, 2009, p. 13).

Vale la pena recalcar que jugó un papel fundamental el contacto que tuvo la CONAMURI con la Coordinadora Latinoamericana de Organizaciones del Campo (CLOC) y la Vía Campesina Internacional, así como el Movimento 
de Mulheres Camponesas do Brasil (MMC). Ambas organizaciones tenían como tema central de debate cuestiones relacionadas a género y clase, lo que posteriormente fue tomado como eje fundamental de la CONAMURI:

\footnotetext{
Dentro de la CLOC - La Via Campesina también se estaba discutiendo fuertemente las cuestiones de género, y ese fue el impulso más importante para organizarnos como mujeres campesinas e indígenas. La MMC se definió como una organización de género y clase dentro del movimiento campesino internacional, y esa fue una posición muy importante como antecedente de la CONAMURI (CONAMURI, 2009, p. 15).
}

Es decir, el haber sentado posición en los ejes género y clase hizo que las mujeres campesinas e indígenas finalmente reconozcan que tal vez sus voces no hayan sido lo suficientemente escuchadas en las organizaciones mixtas, y que era hora de salir de la pobreza y transformar las relaciones entre hombres y mujeres. Este fue el motor principal y mayor diferencial de la CONAMURI en Paraguay, tal y como lo explica en breves palabras Szwako (2012, p. 331, traducción libre, comillas en el original): "es en la construcción de ese ‘espacio propio’ que está la novedad de CONAMURI”.

\section{La invisibilidad de la mujer en los nuevos movimientos sociales.}

La historia nos ha mostrado en varios momentos que la condición de la mujer ha estado relegada al ámbito de "lo privado", sujeta al rol desempeñado dentro de la familia en sus diferentes esferas (sea como esposa, madre, reproductora, entre otros). Esta diferencia histórica con respecto a los hombres se ha "naturalizado", y la acumulación de trabajo (no pagado) en la figura de la mujer se volvió también "una acumulación de diferencias, desigualdades, jerarquías y divisiones que ha separado a los trabajadores entre sí, e incluso de ellos mismos (FEDERICI, 2010, p. 176). 
Esta situación comenzó a cambiar con el proceso de industrialización, tras la inserción de las mujeres en el mercado de trabajo, lo que dio pie a reconfigurar reglas y normas que han sido establecidas por la sociedad así como ampliar la lucha por sus derechos y otras reivindicaciones (FISCHER, 2006, p. 13). Este protagonismo adquirido por la mujer a través de la lucha por el reconocimiento de su posición en el mercado de trabajo permitió su emergencia como nueva actora social política. El desafío al patriarcado y a las prácticas que socialmente se han naturalizado como de mujeres fue lo que hizo constituir al movimiento feminista, lo que significó una sacudida a formas de poder y autoridad legitimadas históricamente, así como lo destaca Raewyn Connell como: "la más clara conquista y consecuencia del movimiento feminista la deslegitimación -fenómeno mundial- de la dominación masculina" (CONNELL, apud ADELMAN, 2016, p. 27, traducción libre, cursivas mías).

A pesar de que los movimientos sociales contemporáneos actúan con base en la redistribución, según los problemas de igualdad de derechos y oportunidades, y el reconocimiento, según la identidad (LAMUS CANAVATE, 2010, p. 46), la deslegitimación mencionada por Connell no significó desentrañar las prácticas patriarcales que se continuaron realizando en diferentes ámbitos de nuestra sociedad como tal, inclusive al interior de los movimientos sociales que luchan por modificar estas cuestiones.

En la experiencia de las CONAMURI, cuando se hacen conscientes de la posición subalterna que ocupan en la lucha del movimiento campesino por el solo hecho de ser mujeres es el momento en el que buscan autoorganizarse a fin de expresar sus inquietudes y reivindicaciones en su propia voz. Esta tensión provocada dentro de la organización podría tomarse como normal, ya que los movimientos sociales por lo general 
tienen debates y quiebres internos, a lo que se añade en la experiencia de las mujeres, "iniciativas y expresiones del movimiento que compiten por espacios, recursos y adhesiones" (LAMUS CANAVATE, 2010, p. 45, cursivas en el original).

Así, las mujeres indígenas y campesinas de la CONAMURI procuran democratizar poderes en los espacios que ocupan y hacer de la horizontalidad del poder una cuestión compartida entre hombres y mujeres, es decir, "hacer rupturas sobre el 'mandar' de élites dominantes o hegemónicas" (CONAMURI, 2009, p. 18, cursivas mías). Estas rupturas tienen que ver con lo que Adelman (2016, p. 63, traducción libre) llama "una crítica profunda a las relaciones de poder del orden existente y de la cultura en la cual este se sustenta", ya que si bien muchos otros movimientos sociales han reclamado históricamente esta cuestión, las mismas campesinas e indígenas notaron que estas relaciones también permearon al interior de las organizaciones mixtas en las que solían militar ${ }^{4}$. Se afirma así la incorporación de una contradicción en discursos y movimientos rebeldes denominada "sesgo cultural histórico masculinista" (ADELMAN, 2016, p. 32, traducción libre), lo que requirió un posicionamiento de las mujeres al respecto.

Aquí es donde se encuentra la invisibilidad de la mujer que, específicamente hablando sobre el movimiento campesino e indígena en Paraguay, ha sido relegada a roles "naturalmente" asignados, como cocinar, ser la secretaria del movimiento o a la de amenizar las reuniones o encuentros. Sobre el

4 Adelman (2016, p. 64, traducción libre) menciona a la historiadora estadounidense Sara Evans, quien afirma que estas contradicciones también fueron percibidas por las jóvenes que luchaban en los movimientos de liberación femenina: "Había aquellas que surgieron en el seno de los propios movimientos, en los que los discursos libertario, democrático y / o socialista se detenían frente a los privilegios masculinos del monopolio de la palabra y del liderazgo político”. 
punto, Szwako (2012, p. 328, traducción libre) señala que estas contradicciones internas generaban conflictos con quienes, a más de ser compañeros de militancia, también eran esposos, hermanos o hijos, ya que el intento de las mujeres en ocupar cargos que "tradicionalmente" habían sido de hombres se tomó con desconfianza y hasta una amenaza de división o quiebre del movimiento.

Sin embargo, las mujeres de la CONAMURI han sabido plantear un acercamiento a los sectores que se mostraron reacios o desconfiados ante estas acciones a fin de lograr la visibilidad que merecían dentro y fuera del movimiento:

\begin{abstract}
Nuestra experiencia muestra que 'imbeguevé la proceso organizativo de las mujeres'5 porque tenemos un doble condicionamiento y menos oportunidades. Enfrentamos el desafío de compatibilizar nuestras tareas de cuidado de la casa y los hijos/as con nuestra participación en la organización. Las compañeras tenían dificultades para participar en las reuniones y en las actividades de la organización porque no tenían con quien dejar a sus hijos/as. Esta situación nos enseñó que era necesario sensibilizar a los compañeros para que compartan las tareas de cuidado e involucrarlos para entender la lucha de las mujeres (CONAMURI, 2009, p. 19, cursivas mías).
\end{abstract}

En este punto, es necesario enfatizar que a partir de la necesidad que tuvieron las mujeres del CONAMURI de sensibilizar a los compañeros para entender la lucha y hacer de la causa una verdadera unión de fuerzas, se han replanteado las reivindicaciones del movimiento desde la propia experiencia de las mujeres, sin olvidar la de los hombres. Así, Lamus afirma que estos cuestionamientos al patriarcado a partir del feminismo han producido "fisuras importantes en los paradigmas dominantes y enriquece los debates en torno a los movimientos sociales, al tiempo que ubica en el escenario político subjetividades subalternizadas por tales paradigmas" (LAMUS CANAVATE, 2010, p. 47). Es decir, el repensar las experiencias de las

5 Del guaraní: “es muy lento el proceso organizativo de las mujeres”.

Rev. Sociologias Plurais, v. 4, número especial 3, p.85-102, nov. 2018 
mujeres en la sociedad desde la crítica feminista, según Adelman (2016, p. 95, traducción libre), implica hacerlo "en toda su historicidad y especificidad, esto es, a partir de las relaciones de poder entre los géneros y su intersección con otras formas de relaciones sociales, particularmente las de clase, raza/etnicidad y orientación sexual”.

\section{Ser mujer, del “tercer mundo”, rural o indígena.}

Dar una mirada diferente a las experiencias de las mujeres, intentando hacer una nueva lectura a partir del género y su intersección con otras relaciones sociales da paso a lo que se conoce como perspectiva interseccional. Kimberlee Crenshaw es la autora que acuñó este concepto, si bien en forma provisoria, al detectar cómo las categorías raza y género interactúan e impactan en diferentes dimensiones de la experiencia de trabajo de mujeres negras. A su ver, las razones por las cuales la identidad se construye en el mundo social pueden (y deben) ser entendidas desde la categoría clase, orientación sexual, edad, color, entre otros (CRENSHAW, 1991, p. 1244). Específicamente, al realizar un análisis interseccional se puede conocer diversos tipos de discriminación existentes según el contexto en donde se originan y las experiencias abordadas por distintas identidades. En suma, este análisis permite reconocer cómo se crean estas desigualdades y estructuran las posiciones de las personas en una sociedad determinada (SYMINGTON, 2004, p. 2).

Desde esta perspectiva, el caso de las CONAMURI cobra importancia al detectar su situación de desigualdad en la sociedad debido a la dictadura patriarcal, que condiciona a las mujeres no solamente a la subordinación por causa de su sexo, sino que utiliza esta cuestión para lograr perpetuarla en prácticas sociales asumidas como "naturales" y que provocan brechas de desigualdad en ámbitos como el laboral, cultural, social, político, entre 
otros. Particularmente, las mujeres del CONAMURI mencionan que antes de conformar su propio grupo, en el sector rural o indígena era raro encontrar grupos autónomos de mujeres. Difícilmente ocupaban posiciones de decisión, sin contar el poco o nulo reconocimiento por el trabajo realizado. Inclusive, las indígenas no figuraban en las estadísticas. Este hecho hizo que piensen en construir un propio espacio en Paraguay para que las mujeres rurales e indígenas consigan participar plenamente, desarrollar sus potenciales y dejar atrás la situación de opresión y explotación a la que eran sometidas no solo por ser mujeres, sino indígenas o campesinas (CONAMURI, 2009, p. 13).

Otra cuestión particular del caso de las CONAMURI que se puede distinguir desde esta perspectiva es el hecho de estas mujeres campesinas e indígenas agruparse de forma independiente a las mujeres urbanas. Las múltiples identidades que se congregan en esta organización hacen que sus reivindicaciones sean diferentes a las feministas de la ciudad debido a la situación económica y social que las afecta directamente. En sus palabras, ellas mencionan "el hambre, la falta de tierra, las diferentes formas de violencia, el analfabetismo, la mortalidad materna, la sobrecarga de trabajo, la preocupación por los bosques y el agua, ya que estábamos sintiendo la falta de agua y leña” (CONAMURI, 20o9, p. 16). En este punto, es claro que estos problemas no encajan en el contexto de la mujer urbana promedio que, teóricamente, tiene mayor facilidad de acceso a servicios de calidad como salud, vivienda, educación, especialmente en Paraguay donde aún se encuentran centralizados en dos o tres ciudades grandes (Asunción, Ciudad del Este, Encarnación). Esto, sin olvidar que existen en las ciudades mujeres que viven en condiciones de extrema pobreza, o indígenas y campesinas como parte de un proceso migratorio del campo a la ciudad. Aquí radica la importancia de la interseccionalidad, ya que no solo se tiene en cuenta el 
entrecruce de desigualdades sino el contexto necesario para entender la magnitud de la experiencia de discriminación.

Por otra parte, en conjunto con la teoría feminista, la teoría poscolonial va tras la recuperación de lo que conocemos como "el Otro de la modernidad occidental" (ADELMAN, 2016, p. 199, comillas en el original), es decir, las vivencias que se acallaron, se invisibilizaron y que, históricamente, se construyeron como ese Otro. Más allá de cualquier binaridad, se rescata cómo a partir de la deconstrucción de este Otro creado por un discurso hegemónico se conocen “experiencias diferentes más plurales de los 'nuevos sujetos', nuevos en término de reconocimiento reciente por el mainstream, diferente de su larga participación histórica, y el carácter relacional y no de oposición del concepto de alteridad" (ADELMAN, 2016, p. 202, cursivas en el original).

Para conocer a fondo la realidad de las mujeres de la CONAMURI, se puede tomar la sugerencia de Adelman (2016, p. 211, traducción libre) sobre el trabajo de las feministas poscoloniales, haciendo mención al proyecto desarrollado por Edward Said en su libro Orientalismo: "La crítica de la representación de la mujer no occidental, caracterizada como Otro en un sentido triple: como mujer, como no occidental y, en tercer lugar, en una posición particular producida por la unión de los otros dos términos”. En este sentido, se puede relacionar esta posición particular a la cuestión de la etnicidad para que, desde la perspectiva interseccional, se pueda entender finalmente lo que implica la resistencia de las CONAMURI al ser mujer, “del tercer mundo", rural o indígena. 
Acerca del "tercer mundo", si bien requiere un debate mucho más amplio que escapa de las posibilidades de este trabajo, al hablar de la modernidad occidental y su deconstrucción conviene conocer la forma en que Chandra Mohanty utilizó este término a fin de explicar cómo una parte de la corriente feminista occidental constituyó en sus discursos académicos la rígida categoría “mujer del tercer mundo". La crítica que esta autora realiza tiene que ver con que esta categorización despersonaliza elementos como raza, etnia, clase u origen al punto de construir "una noción homogénea de la opresión de las mujeres como grupo" (MOHANTY, 1984, apud SUÁREZ NAVAZ, L; HERNÁNDEZ, A, 2008, p. 5).

Como resultado, se crea una imagen discursiva de "la mujer promedio del tercer mundo" (pobre, ignorante, sin educación, víctima), en suma, una mujer oprimida carente de poder, privilegiando en oposición la imagen de la “mujer occidental”. Pensar en esta lógica del "tercer mundo" deriva de una visión evolucionista del "primer mundo" como lo desarrollado y el Otro como el "subdesarrollo". Colocándolo en el análisis feminista, Mohanty afirma que "al homogeneizar y sistematizar las experiencias de distintos grupos de mujeres en estos países, borra todos los modos y experiencias marginales y de resistencia” (MOHANTY, 1984, apud SUÁREZ, L; HERNÁNDEZ, A, 2008, p. 19). Entonces, la teoría poscolonial lo que hace no es colocar un binomio mujer occidental/mujer del tercer mundo, sino enfatizar la existencia de diversas realidades, que tienen una propia historia, una propia cultura, diferentes entre sí (ADELMAN, 2016, p. 215, traducción libre).

$6 \quad$ Sobre el uso del término "tercer mundo" (comillas incluidas), Chandra Mohanty explica que si bien puede "sugerir una similitud sobresimplificada entre las naciones así denominadas, como reforzar jerarquías económicas, culturales e ideológicas existentes", la intención es dar un uso crítico y colocarlo en cuestión constante. 
La CONAMURI es un claro ejemplo de una experiencia de resistencia que por mucho tiempo ha permanecido invisible pero que a partir del contacto con otras mujeres cuyas experiencias de opresión han sido similares comenzó a cobrar autonomía. Tuvo mucha influencia el hecho de pensar en ellas mismas como portavoces de sus experiencias a fin de transformar las relaciones de poder que hacen parte en los diferentes espacios en que se desempeñan y hacer oír verdaderamente sus voces en esferas de decisión como la política. También es importante remarcar que si bien no ha sido un camino fácil para ellas, el aprendizaje realizado a partir de pensar propuestas, ser críticas, negociar, decidir, perder y ganar hizo que lograran autorreconocerse, construirse y constituirse como verdaderas actoras políticas en busca de un modelo de poder basado en igualdad de derechos y condiciones (CONAMURI, 2009, p. 20).

En suma, desde la teoría poscolonial es posible conocer la profundidad de la marginalización de las experiencias de estas mujeres al analizar su situación desde estos ejes de desigualdad social (género, etnia, clase) que se entrecruzan en ellas: ser mujer, ser indígena o rural, ser considerada "del tercer mundo". Esto permite alcanzar una visión multicultural ya que da centralidad al complejo juego que constituyen las relaciones de raza/etnicidad, clase, orientación sexual, género, nacionalidad, teniendo en cuenta la especificidad e historicidad (ADELMAN, 2016, p. 214, traducción libre).

\section{Consideraciones finales}

A lo largo de este trabajo se buscó exponer razones por las cuales la Coordinadora Nacional de Organizaciones de Mujeres Trabajadoras, Rurales e Indígenas (CONAMURI) se constituye como tal, de forma independiente en relación al espacio de resistencia del movimiento campesino e indígena 
en Paraguay. Este análisis fue realizado desde la teoría feminista y la poscolonial, con aportes desde la perspectiva interseccional.

Una de las cuestiones más relevantes radica en cómo la desigualdad ha marcado históricamente la experiencia de estas mujeres hasta el punto de haber sido invisibilizadas, paradójicamente, dentro de los movimientos sociales desde los cuales hacían resistencia. Es decir, el que la dictadura del patriarcado haya permeado al interior de la resistencia fue uno de los factores que provocó esta necesidad de un espacio propio a fin de acabar con la doble situación de exclusión y opresión y conseguir la democratización de las relaciones de poder en sus ámbitos de acción.

Otra cuestión relevante y de influencia para lograr esta autonomía fue el contacto con organizaciones internacionales como la CLOC, la Vía Campesina Internacional y el Movimento de Mulheres Camponesas do Brasil. El haberse reconocido e identificado con experiencias similares y, sobre todo, el conocer cómo estas organizaciones trabajan sus reivindicaciones basadas en los ejes etnia, género y clase, permitió que las mujeres rurales e indígenas de la CONAMURI lograran la visibilidad de su lucha en Paraguay.

La necesidad de construir soluciones alternativas que consideren la propia experiencia de discriminación que han vivido estas mujeres habla del desconocimiento del contexto social e histórico en el que desenvuelven sus vivencias; así también, el impacto que tiene el hecho de que en ellas se entrecrucen los ejes de desigualdad que afectan profundamente a nuestra sociedad. Estas dos razones justifican el que se hayan organizado y fortalecido como una organización de clase, etnia y género, ya que, como ellas mismas mencionan: "las mujeres vivimos la discriminación no solo 
como pobres y trabajadoras, por hablar guaraní o por ser indígena, sino por el mismo hecho de ser mujer... topa ñemboyke7” (CONAMURI, 2009, p. 39).

La teoría feminista y la poscolonial, así como el análisis interseccional, son herramientas que permiten alcanzar una visión multicultural sobre este caso, principalmente debido a la necesidad de reconocer las múltiples identidades que se congregan en esta autoorganización de mujeres rurales e indígenas en Paraguay. En un intento de combatir el binarismo reduccionista mujer carente de poder / mujer con poder, o las imágenes homogeneizadas de experiencias y opresión "tercermundistas" construida por el discurso hegemónico patriarcal y occidental, lo que se procura aquí es entender verdaderamente el contexto de la lucha de estas mujeres por la igualdad.

\section{REFERENCIAS}

ADELMAN, Miriam. A voz e a escuta: encontros e desencontros entre a teoria feminista e a sociologia contemporânea. 2. Ed. São Paulo: Editora Blucher, 2016.

ADELMAN, Miriam; GROSSI, Miriam; GUIVANT, Júlia. A teoria feminista e as perspectivas de gênero na teoria social contemporânea: contribuições $e$ debates. In: GROSSI, M. P; LAGO, M. C.; NUERNBERG, A. H. (org.) Estudos In(ter)disciplinados: Gênero, feminismo, sexualidade. Florianópolis: Ed. Mulheres, 2010. P. 21-40.

\section{CÁMARA PARAGUAYA DE EXPORTADORES Y COMERCIALIZADORES DE CEREALES Y OLEAGINOSAS Ranking mundial (2018). c2018. Disponible en <http://capeco.org.py/ranking-mundial-es/> Acceso en 20, febrero, 2018.}

7 Del guaraní: que se acabe la discriminación. 
CONAMURI. ¿Quiénes somos? (2018) c2018. Disponible en <https://www.conamuri.org.py/quienes-somos/> Acceso en: 2 ene. 2018.

CONAMURI. Mujeres en rebeldía y resistencia. Kuña jetyvyro ha jepytaso. Nuestro camino. Ñande Rape. Sistematización de nuestros relatos. Ñane Ñe'e. Asunción: CONAMURI, 2009.

CRENSHAW, Kimberlee. Mapping the Margins: Intersectionality, Identity Politics, and Violence Against Women of Color. Stanford Law Review [online]. v. 43, n. 6, p 1241-1299, jul, 1991, Stanford. Disponible en <http://www.jstor.org/stable/1229039> Acceso en: 20, febrero, 2018.

FEDERICI, Silvia. Calibán y la bruja. Mujeres, cuerpo y acumulación originaria. Madrid: Traficantes de sueños, 2010.

FISCHER, Izaura Rufino. O protagonismo da mulher rural no contexto da dominação. Recife: Editora Massangana, 2006.

LAMUS CANAVATE, Doris. De la subversión a la inclusión: movimientos de mujeres de la segunda ola en Colombia, 1975-2005. Bogotá: Instituto Colombiano de Antropología e Historia, 2010.

MOHANTY, Chandra Talpade. Bajo los ojos de occidente. Academia feminista y discurso colonial. In: SUÁREZ NAVAZ, L; HERNÁNDEZ, A (ed.) Descolonizando el Feminismo: teorías y prácticas desde los márgenes. Madrid: Editorial Cátedra, 2008.

SYMINGTON, Alison. Interseccionalidad: una herramienta para la justicia de género y la justicia económica. Derecho de las mujeres y cambio económico. Asociación para los Derechos de la Mujer y el Desarrollo (AWID). n. 9, ago, 2004. Toronto: AWID. Disponible en <http://www.inmujeres.gub.uy/innovaportal/file/21639/1/2 awid intersecci onalidad.pdf $>$ Acesso en: 25, febrero, 2018. 
SZWAKO, José. Del otro lado de la vereda: luta feminista e construção democrática no Paraguai pós-ditatorial. 2012. $440 \mathrm{f}$. Tesis (Doctorado en Ciencias Sociales) - Instituto de Filosofía y Ciencias Humanas, Universidade Estadual de Campinas, Campinas, 2012. Disponible en <http://repositorio.unicamp.br/handle/REPOSIP/280321> Acesso en: 10, enero, 2018. 